\title{
The Role of People in Information-Sharing: Perceptions from an Analytic Unit of a Regional Fusion Center
}

\author{
Carla Lewandowski ${ }^{1}$ \\ Rowan University \\ Jeremy G. Carter \\ Indiana University - Purdue University Indianapolis \\ Walter L. Campbell \\ Rutgers University
}

\begin{abstract}
Information sharing research has largely focused on capturing operational practices related to the exchange of information. A noticeable shortcoming of this developing literature is the lack of scholarly attention focused specifically on analytic personnel. The present study employs semi-structured interviews with 23 personnel that comprise the analytic unit within a regional fusion center located in a large metropolitan area in the United States. Findings indicate that there is significant ambiguity surrounding the organizational and geographic audiences to which intelligence products should be tailored. Moreover, it appears information sharing is sparse and reliant upon personal relationships between analysts and external organizations. Lastly, analysts do not receive feedback pertaining to the content and effectiveness of intelligence products created. These findings may be generalized to other analytical organizations whose primary goal is to gather, analyze and disseminate intelligence. Action steps for policymakers are provided.
\end{abstract}

\section{Citation:}

Lewandowski, C., Carter, J. G., \& Campbell, W. L. (2017). The role of people in information-sharing: perceptions from an analytic unit of a regional fusion center. Police Practice and Research, 18(2), 174-193. http://doi.org/10.1080/15614263.2016.1250631

${ }^{1}$ Corresponding Author: lewandowskic@rowan.edu

This is the author's manuscript of the article published in final edited form as: Lewandowski, C., Carter, J. G., \& Campbell, W. L. (2017). The role of people in information-sharing: perceptions from an analytic unit of a regional fusion center. Police Practice and Research, 18(2), 174-193. http://doi.org/10.1080/15614263.2016.1250631 


\section{Introduction}

Soon after the terrorist attacks of September 11, 2001, the need for greater information sharing and increased intelligence capabilities across various law enforcement levels and locales became widely apparent (National Commission on Terrorist Attacks, 2004). State and regional fusion centers have been one of the main vehicles for increasing both information sharing and intelligence capabilities by acting as hubs for information and intelligence on terrorist, criminal, and other public safety threats within a particular geographic area (Carter \& Carter, 2009a). The scholarly knowledgebase of fusion centers and other information sharing agencies is rather sparse given the integral role they play in the law enforcement intelligence landscape and the substantial financial commitment invested by federal and state governments to keep them operational (Taylor \& Russell, 2011).

The most robust literature on fusion centers focuses on the experiences of end-users - the agencies that receive intelligence from fusion centers (Carter, 2015; Chermak et al., 2013; Lewandowski \& Carter, 2014; Cooney, Rojek, \& Kaminski, 2011). Far less is known about the experiences of fusion center employees within primary state fusion centers, much less regional fusion centers. As geographic location and agency mission can impact information sharing (Lewandowski \& Carter, 2014; Ratcliffe, Strang, \& Taylor, 2013; Taylor \& Russell, 2011), it is logical to assume that the perceptions of personnel within fusion centers may illuminate some of the unknowns regarding law enforcement intelligence in contemporary society. Perhaps the most salient aspect of fusion centers is the analytic capability they provide to develop intelligence products and assist local agencies. However very little is known about the analytic activities within fusion centers 
or any other analysis center. The present study examines analytic processes and perceptions of analytic effectiveness through detailed semi-structured interviews with personnel that comprise the analytic unit of a recognized fusion center.

\section{Analytic Capabilities and Information Sharing}

In 2007, the Homeland Security Council called for an increased use of intelligenceled policing (hereafter, ILP). While there is no universally agreed upon definition of ILP, Carter \& Carter (2009a, p.317) defined it as "The collection and analysis of information related to crime and conditions that contribute to crime, resulting in an actionable intelligence product intended to aid law enforcement in developing tactical responses to threats and/or strategic planning related to emerging or changing threats.” This proactive, data-driven approach to policing is believed to lead to an increase in situational awareness that helps prevent future terrorist activity and functions as an effective tool in combating crime (Carter \& Carter, 2012; Homeland Security Council, 2007).

One reason that ILP is particularly well suited to address issues of homeland security is the emphasis it places on analyzing and sharing information. A lack of information sharing across various levels and locales of law enforcement has been suggested as a major contributor in the failure to prevent the events that occurred on 9/11 (Zegart, 2007). Full implementation of ILP requires sharing information within and across organizations (Carter, Phillips \& Gayadeen, 2014); without such sharing, data collection is impoverished and so is information and intelligence dissemination (Ratcliffe, 2008; Ratcliffe, Strang, \& Taylor, 2013). 
Yet full adoption of ILP is by no means a simple process (Carter, 2016; Ratcliffe, 2002). The adoption of innovative policing tactics is often an uphill battle (Weisburd \& Braga, 2006), usually requiring substantial organizational change. With high standards for analytic capabilities and multijurisdictional connections, ILP is no exception. As noted by Ratcliffe (2008), adoption of ILP is often hindered by a culture of policing that does not traditionally prioritize information sharing, and by a lack of leaders who understand the potential benefits of ILP. Darroch and Mazerolle, (2012) noted difficulties in ILP implementation in New Zealand due partially to poor leadership and lack of openness to innovation, and Ratcliffe (2005) found that a lack of resources also inhibited adoption in New Zealand. Ratcliffe and Guidetti (2008) found that major organizational change was essential to implementation within the New Jersey State Police, and in spite of this, the program was still met with notable resistance. In short, ensuring that US law enforcement agencies have the analytic capabilities and interconnectedness required for full ILP adoption is not an easy undertaking.

Of the sparse literature examining analysis in fusion centers, and ILP in police agencies more generally, there appears to be consensus that analytic activities lack operational value and the ability to inform actionable outcomes. Graphia-Joyal (2010) employed a qualitative study that included 49 interviews at four fusion centers in the northeast region of the U.S and concluded that these centers had yet to develop a robust analytical capability. Her findings suggested that fusion centers are more apt to provide investigative support that lacked critical analysis. Such findings have been echoed by other scholars examining intelligence-led and analytic-driven policing. In their ethnographic study of four intelligence units from the United Kingdom, Innes, Fielding, and Cope (2005) 
concluded that analytic functions within these units were, in reality, a repackaging of traditional policing data and information. The intelligence units examined attempted to lend a degree of objectivity to the products created as a result of an analytic process that lacked any true scientific application. This may be the result of what Cope (2004) contends to be a cultural disconnect between analysts and police personnel as well as a general lack of understanding as to how analysis can influence police practice. In their study of Canadian police intelligence units, Sanders, Weston, and Schott (2015) found that intelligence production and information sharing were steeped in rhetoric and contingent upon an agency's culture to embrace innovative analyses. Though each agency appeared to institutionalize analytic work, actual intelligence analysis was an exception rather than the rule. Explanations for this analytic and cultural disconnect remain unknown in the literature and is a focal point of the present study and a strength of the qualitative design employed.

\section{Information Sharing through Fusion Centers}

While the idea of state and regional collaborative centers is not new to law enforcement (Carter \& Carter, 2009b), the rise of contemporary fusion centers occurred simultaneous to the emergence of ILP within the United States, making their convergence especially opportune. In the highly fragmented U.S. law enforcement environment, there is great value in the potential for fusion centers to streamline ILP adoption by providing a form of centralization. With currently 53 state and 24 regional fusion centers spread throughout the country, each center is designed to cover a specific geographic area, connecting local, state, and federal law enforcement, emergency services, transportation 
services, and a wide variety of private businesses within that area (Taylor \& Russell, 2012).

Further, the capacity of these centers to collect, distribute, and analyze raw information can act as a force multiplier that enhances the analytic capabilities within their areas of operation (Saari, 2010).

Implementing ILP requires substantial resources (Carter \& Phillips, 2015). Cooney et al. (2011) found that the state fusion center in South Carolina was able to act as a support service for those agencies that wished to implement ILP but lacked the necessary resources. A similar finding was noted by Lewandowski and Carter (2014) in a study of a state fusion center. This role of fusion centers seems to be particularly important for smaller agencies as they typically lack dedicated intelligence capabilities (Riley et al., 2005) and are far less prepared for emergency situations (Burruss et al., 2010). The need for additional support among small agencies suggests that regional fusion centers, with their restricted geographical focus, may play a particularly important role in the expansion of ILP and information sharing.

\section{Qualitative Context and Regional Fusion Centers}

Due to their comparative infancy in the criminal justice infrastructure, only a small, but growing body of research currently informs the effective functioning of fusion centers. While this small body of research has provided substantial insights into the ways that fusion centers affect information sharing and ILP adoption, very little of this research has involved the sort of in-depth examinations that allow for a more complete picture of how the information sharing environment is shaped by the mundane experiences of those involved. Further, while there is good reason to believe that regional fusion centers may take on 
different roles and find themselves in different contexts than state fusion centers, no research has specifically examined the environment in which they operate.

To date, much of the fusion center research has taken the form of survey research (Carter, 2015; Chermak et al., 2013; Lewandowski \& Carter, 2014; Cooney et al., 2011). While these studies have leant great insight into changes in information sharing, the activities of centers, and the attributes of end- users across the United States, for what these methods gain in generalizability, they lack in detail (Carter, 2015). Chermak, et al. (2013) note that while their study allows them to identify patterns of information sharing that hold across various fusion centers and fusion center end-users, it does not allow them to dig deeper into the reasons for their findings. Carter (2015) urged for such in-depth studies to better identify the determinants of information sharing. Few studies have explored fusion center functioning through in depth interviews; those that do have shed valuable insights. The in-depth interviews conducted by Lewandowski and Carter (2014) allowed for a more nuanced understanding of their survey results that alone were rather ambiguous. As Graphia-Joyal (2010) noted in her study of those affiliated with four state fusion centers, interviewing personnel allowed for exploration of "poorly understood contexts and constructs” (p. 362), providing a richer set of data that helps inform future policy and research.

In addition to this methodological gap in the literature, there is also a substantive shortcoming. While much attention has been paid to the experiences of end-users (Carter, 2015; Chermak et al., 2013; Cooney et al., 2011; Lewandowski \& Carter, 2014) and state fusion center employees (Gaphia-Joyal, 2010; Lewandowski \& Carter, 2014; Saari, 2010), research has yet to address the experiences of regional fusion center employees. Regional 
fusion centers are representative of a third of existing centers and merit greater academic attention. This is especially true considering existing research on information sharing and ILP that suggests regional fusion centers may more closely align to ILP and local law enforcement. First, departmental mission and leadership are important components in the adoption of ILP (Ratcliffe, 2005; Ratcliffe, 2008; Ratcliffe \& Guidetti, 2008; Ratcliffe et al., 2013). Regional fusion centers are often administered by local law enforcement as opposed to state police. Thus regional centers may have noticeably different goals and styles of leadership than primary state fusion centers.

Second, location matters. Burruss et al. (2010) concluded that proximity to a major city affected homeland security preparedness among small police departments. Saari (2010) found that different fusion centers may have different focuses simply as a result of their geographic location. Both Cooney et al., (2011) and Lewandowski and Carter (2014) found that end-users cared most about intelligence that was close to their geography. Unlike state fusion centers, regional centers are often located in a major metropolitan area and have a much smaller area of operation; making the sorts of issues they face and relationships they have with-end users inherently different from those of the state fusion centers. Lastly, perceived similarity is associated with increased information sharing between departments (Lewandowski \& Nestel, 2016; Roberts \& Roberts, 2007; Weiss, 1998). For regional fusion centers, the agency in charge, most likely to be the local municipal police department, will more closely emulate the structure of other local agencies than will a state fusion centers which are generally run by state police.

In sum, it is logical to assume that the fidelity observed across state and regional fusion centers will mirror that of state and local law enforcement. Research from state 
fusion centers may therefore not be representative of regional fusion centers. More specifically, the types of relationships and intelligence discovered in regional centers may provide new insights regarding the manner in which information is shared and ILP is practiced. This study aims to inform this scholarly shortcoming with twenty-three in-depth interviews with analytic personnel within a regional fusion center operating in a major metropolitan area.

\section{Methods}

Greene (2014) challenged scholars to balance quantitative prediction and qualitative context in policing research. He argued the evidence-based movement, while beneficial for a number of reasons, diluted the "cognitive lens" (p. 193) through which meaning could be gleaned from research and used to inform practice and future inquiry. He further contended that such qualitative context is most appropriate for areas of policing research where little is known and dangers could arise if drawing interpretations from statistics alone. The present study embraces this approach and employs a qualitative semistructured methodology to glean perceptions of intelligence analysis from fusion center analytic personnel. This methodological approach is advantageous in that it allows for a nuanced and contextualized understanding of practices and issues. King (1994) notes that semi-structured approaches are most appropriate for research that is exploratory and nuanced as this method relies on open-ended questions that result from probing by the researcher and often times a free-flowing dialogue is created that guides the interview process. 
Moreover, research data is difficult to obtain from fusion centers given the sensitivity of intelligence-related topics and intelligence personnel's unwillingness to discuss their work (Chermak et al., 2013; Carter, 2015; Lewandowski and Carter, 2014). This has led to a lack of empirical research in this field especially regarding the employees intended to be the medium through which information is shared, analyzed, and disseminated. This qualitative methodology not only allows for the nuanced nature of information sharing and analysis to be captured, but it also creates a research environment in which a rapport can be developed between the intelligence personnel and the researchers. As a result, this methodological design is best positioned to maximize the collection of desired data.

Despite the limited literature on fusion centers, the researchers leveraged previous research on fusion center and intelligence sharing in contemporary law enforcement to construct the semi-structured interview instrument. This instrument focused on key operational aspects of law enforcement intelligence, information sharing, and analysis. More specifically, questions were contextualized within the fusion center environment and directly related to the impact on state and local law enforcement. A combination of researcher notes and audio recordings of each interview were transcribed into a single source document. To enhance the validity of interpretations from the interviews, additional teleconferences and continual communication exchanges with fusion center personnel occurred to solicit feedback, clarify and reaffirm the information gathered. Confirmation of perceptions is especially prudent given the sensitive nature of the research topic and the limited literature to which results can be compared and contrasted. The research team wanted to ensure a comprehensive understanding of the analysts' views of the intelligence 
products they created and the intelligence-led practices their products were intended to inform.

\section{Study Context: Organizational Characteristics}

As perceptions of organizational operations within policing have been shown to vary across personnel within the same organization (Rosenbaum, 2002), the present study utilizes interviews with each personnel member assigned to the fusion center's analytic capacity. The fusion center at which the research was conducted is located in the U.S. and is designated by the U.S. Department of Homeland Security as one of 78 "Recognized Fusion Centers” (U.S. Department of Homeland Security, 2016). A recent report by the U.S. Department of Homeland Security (2013) documented the organizational capabilities and practices of each fusion center nationwide and quantified operational scores for each center across a range of metrics. Based on these metrics, the fusion center of study in the present research received an "average” overall rating compared to centers across the country. This rating lends credence to the generalizability of the findings to be presented in the current study as the operations and practices of the center of study are consistent with those nationwide. Relatedly, Appendix A provides a list of organizational capacities, policies, and practices for the fusion center under study. These organizational characteristics are provided to best contextualize the organization from which the analyst perceptions and findings of the present study were observed.

The fusion center of study, overseen by a large municipal police department, has an analytic unit of 28 personnel; 24 analysts and four analyst supervisors. Each person is assigned full-time to the fusion center. All analytic personnel were initially e-mailed by the 
supervisor who stated that the research team would be e-mailing to make an appointment with them for a study being conducted at the fusion center. This assured the employees that approval had been granted for them to speak to the researchers and that there was organizational buy-in from supervisors. The research team reached out to the personnel and asked them to participate in a voluntary study; the team then conducted interviews at the fusion center in a private conference room. The interviews were conducted over the course of six months. Of the initial list of 28 employees, three were out on sick leave or on a tour of duty for the military while two others were unable to be scheduled for interviews due to logistical problems. A total of 23 persons, consisting of all 21 analysts and two supervisors were interviewed for 45-60 minutes; representing 82 percent of the personnel from the fusion center's analytic unit. Respondents had been employed by the fusion center for an average of 18 months (range of three to 43 months). Employees that were hired during the course of the study were not interviewed; additionally, there were four employees that were interviewed who were reassigned or left the fusion center during the course of the study. Analytic personnel primarily came from a state and local law enforcement background (70\%) with the remainder comprised of a mix from various outside federal and local agencies, a composition consistent with fusion centers from across the country (U.S. House of Representatives, 2013).

In the analysis, we make a distinction between civilian analysts and police analysts. Police analysts ( $43 \%$ of the sample) are those analysts who are sworn police officers of the lead municipal agency who are temporarily assigned to the fusion center as an analyst. They have generally received at least one analytical training course and may attend occasional workshops held at the fusion center. Conversely, civilian analysts (57\% of the 
sample) are those who are not sworn officers and whose training is often more extensive and can include courses offered by DHS including risk analysis training specifically for fusion center analysts, introductory and intermediate risk assessment courses as well as cyber security training,

\section{Analytic Strategy}

The survey instrument utilized in the present study is provided in Appendix B. Nvivo (v10) software was utilized to organize and identify thematic constructs from the qualitative information gleaned from the interviews. Key response traits, indicators, and themes were reviewed and agreed upon by the research team. To enhance the validity of interpretations from the interviews, additional teleconferences and continual communication with fusion center personnel occurred to solicit feedback, clarify, and reaffirm the information gathered (King, 1994). Though the research team identified additional information believed to be insightful, only the findings which gained saturation and consensus among those interviewed are reported.

Saturation of qualitative findings is a subjective threshold (Fusch \& Ness, 2015) with debate surrounding necessary sample size (O’Reilly \& Parker, 2013). Guest, Bunce and Johnson (2006) note that data saturation may be attained with as little as six interviews. The present study sought to establish saturation using three methods. First, individual interviews were employed as opposed to focus groups of analytic personnel. This allowed the research team to safeguard against the limitation of groupthink in that dominant members of a group, or position types (such as supervisors) may pressure others to conform to group consensus (MacDougall \& Baum, 1997). Second, different personnel types were 
interviewed that included analysts and analytic supervisors. This personnel diversity allows for the triangulation of individual perceptions of different personnel types to converge on consistent themes (Denzin, 2012); thus strengthening the reliability and validity of qualitative findings (Stavros \& Westberg, 2009). A saturation grid was employed to crosstabulate qualitative data across respondents and positions to demonstrate levels of saturation (Brod et al., 2009).

\section{Findings}

Perceptions from the fusion center personnel were insightful and clustered within four areas pertaining to intelligence analysis; two of which were deemed primary and two secondary based on respondent feedback. The two primary areas of concern for analytic personnel were the sources of information and recipients of the analytic products. Sources of information pertain to the databases, online web content, and law enforcement products analysts rely on to develop intelligence products. Recipients of analytic products are the intended audience to receive disseminated intelligence products from the fusion center (i.e., persons on the listservs). These areas represent the issues most commonly broached, and emphasized, by the respondents. Secondary issues were related to feedback and geographic focus of analytic products. Feedback pertains to commentary or reaction from end-users (recipients) of the intelligence products disseminated. The geographic focus of analytic products refers to municipalities, counties, or jurisdictions to which intelligence products are tailored. These issues are categorized as secondary as they were not mentioned by respondents as frequently, but were emphasized as salient to the analytic mission of the fusion center. Findings are presented in a manner consistent with these themed focal areas. 


\section{Sources of Information}

Creating actionable intelligence products is a critical function of fusion centers. In an era of competitive budgets, entities need to demonstrate their value through a unique capacity to inform stakeholders of intelligence they would not have otherwise received. Central to this ability is access to quality information that can be integrated into the analytic process. The premise of fusion centers is that information from more diverse sources gleans more accurate intelligence (Clark, 2007). The "fusion" of raw information adds to the collective body of information for analysis which leads to a better output (Carter \& Carter, 2009b). Respondents were asked two main questions that pertained to raw information: "Can you please describe the sources of information and data that you use when creating intelligence products?" and "Which sources of information are most useful and do you most frequently utilize?”

A large majority of those interviewed (78\%) stated that open sources were used to provide information for creating products while a large percentage (43\%) further stated that open sources were used exclusively. Many respondents seemed to use a combination of sources even if open source reporting was the main source. "Media reports, some government open source portals provide a little bit more targeted, open source materials through controlled web-logging and opensource.gov. We use SAR reporting and limited police reporting. We also do our own qualitative collection through interviews.” Respondents indicated that open sources included mainstream media (such as CNN and 
FoxNews) and social media, which one interviewee acknowledged was "a Pandora’s box because it is not entirely accurate.” More of the civilian analysts acknowledged that they use what is believed to be more reliable open sources such as, "government open source portals (which) provide a little bit more targeted open source materials...(and) SAR reporting and limited police reporting." When probed for specifics, the portal of government open source material was identified as the Open Source Center ${ }^{2}$ operated by the Office of the Director of National Intelligence in addition to "HSIN, opensource.gov, and Tripwire...i.e. not just open source media types of things”. This portal essentially serves as a government-run data mining tool to capture and categorize publicly available information that may be queried by pre-approved law enforcement personnel.

While some end-users may not necessarily appreciate the inclusion of open source material in the bulletins (Lewandowski \& Carter, 2014), the reason for the reliance on open source information is because of the medium by which the bulletins are sent out. E-mails are sent to a variety of listservs that include both law enforcement and the private sector. Because end-users cannot receive classified information, the bulletins cannot be classified. Despite having "access to classified information through our system” the analysts "do not write anything or produce anything at a classified level for dissemination. (They) usually take those and bring them down to an FOUO (For Official Use Only) or LES (Law Enforcement Sensitive) level.” A supervisor reiterated the importance of not being able to disseminate classified information: "The secure sites would never be cited as a source. We use it to confirm something and it would have to be supported with open source information. We would never disclose anything from the secure room on the lower classified side.” This

\footnotetext{
${ }^{2}$ https://www.opensource.gov/public/content/login/login.fcc
} 
policy is consistent with national fusion center standards for intelligence sharing (U.S. Department of Homeland Security, 2013). During one of the follow-up telephone discussions with one of the analyst supervisors it was discovered that the fusion center has since developed a website and a secure network that users can sign into if they have the necessary clearance.

Civilian analysts who had more training than the police analysts stated that the use of open sources was not problematic as many of them saw their work as necessary for informing the private sector by looking for any communication regarding transportation, railways, gas, water, or electricity that could disrupt private sector operations. They saw their role as one in which they vetted the information for their stakeholders. In agreement with a supervisory analyst, many acknowledged that open sources should be used as a tool for secondary information rather than a primary resource. This respondent explained, “There's a lot of media reporting which...should be used...to go conduct further research on an incident. So, for example, if an incident happens in [city], you are getting the law enforcement side of it through communications, but you're also monitoring the media reporting side so you can kind of confirm information from a variety of different sources.” Interviews with analysts confirmed this approach of using open sources for analysis, but civilian analysts were more likely to perceive value in this type of information sharing than the police analysts. This could be because the civilian analysts have more training than the police analysts and are more likely to understand the value of confirmed intelligence; moreover, they may be more knowledgeable of additional open source databases that they can search to find more information. 
In addition to open sources, respondents indicated Fusion Center Liaison Officers (FLO) and other law enforcement agencies as a preferred and reliable source of information for analytic products. One analyst indicated, however, that while he would like more information from the FLO and local police, this type of information "relies on officers at the district level to provide reporting up the chain to the (fusion center) which is pretty atrophied. I wish we had greater access to the district level police reporting, however, there's not a standardized report format or procedure for sending those reports up, so there's a kink at many levels in the information flow.” The majority of persons interviewed (70\%) indicated that there is also little or no information received from external agencies. Civilian analysts saw this as a problem of marketing and not having enough outreach whereas police analysts saw this as a problem of buy-in from the police officers and agencies in the fusion center's area of responsibility. As a result, analysts must rely on the databases to which they have access.

Analysts who believed that information sharing was lacking stated that this obstacle not only applied to exchanges across different agencies, but also lacking from federal agencies to local agencies; moreover, information sharing within the same local agency could, at times, be limited despite existing within the same organization and committing to the ILP philosophy. Approximately 25 percent of the analysts interviewed surmised that this lack of sharing could be attributed to "personality conflicts". This led to what one analyst referred to as politics; she believed sharing would improve if "a very strong leader could kind of bring the building together. I think the collective is quite strong and there is a lot of talent but people are starting to get down by the politics.” This was reiterated by about 43 percent of the analysts who stated that the sharing mindset has to "come from the 
commissioner to say you will support this and any efforts to sabotage it or negate its effectiveness need to be dealt with harshly.” There was also evidence that police analysts believe the information sharing that does occur is a result of personal and trusted relationships between an analyst and the person sharing the information from the outside agency: "I only get information because I can call my friend in (nearby town) who worked in our department for ten years.” Another police analyst reiterated this point by saying that much of his understanding of the needs of the end-users comes from "people I talk to in passing when I say I work at the (fusion center).” This finding is rather intuitive as police analysts already have a network from which to gather information; on the other hand, civilian analysts hired at the fusion center years after the center was established could not rely on information from acquaintances because they did not have any when beginning work at the fusion center. Instead they relied on their formal training for gathering information.

\section{Product Recipients}

Once information is gathered by analysts at the center, it must then be analyzed and communicated into products that the audience will find actionable. The audience or endusers are an important factor in determining product content. If the intended audience was local law enforcement, analysts would consider the creation of situational awareness or officer safety bulletins. These types of informational bulletins would look very different from those that target security personnel within the private sector. This understanding of the nuances involved in writing toward a specific audience is reflected by half of the respondents, mostly civilian analysts, who stated that the intended audience is evaluated 
on a case-by-case basis. Bulletins are written for specific audiences such as first responders, law enforcement, the private sector, or even specific law enforcement agencies, like a particular transit agency. One analyst acknowledged that "some information is directly geared to a specific police department, police departments generally, departments within a specified county, or it is directly related to the health department or to the FBI. It depends on the information received.” An analyst that stated they were specifically responsible for counterterrorism felt that the fusion center's "main customer in my view should be the mayor of (major city)" because they respond to emergencies. This analyst was the only one who believed that the mayor should be the designated customer.

Forty three percent of respondents stated that they felt the intended audience was a general law enforcement audience. It seems this position was held by many of the analysts who had come from the local police agency. One analyst explained that this was due to "the nature of world today (which) is some active shooter or terrorism tips, suspicious activity reporting, things like that. We don't do much specifically geared towards specific sectors unless we have a reason.” We surmise that the difference in views of audience may stem from a more narrow view on behalf of the police officers who later became analysts. While they do a good job of evaluating the needs of the local law enforcement community, they may be less proficient in understanding the intelligence needs of the private sector or other sectors outside law enforcement.

All of the analysts indicated their knowledge of several lists to which an analyst could disseminate products. There are For Official Use Only (FOUO) and Law Enforcement Sensitive (LES) listservs for which analysts can disseminate law enforcement-specific bulletins. The respondents that indicated developing products for a 
general law enforcement audience believed it was their job to disseminate information to as many people as possible within their legal authority; thus promoting an environment of open information sharing. Analysts alluded to an understanding that this meant intelligence products need to go to an audience that has "a right or legal authority to know (which) dictates who anything is going out to.” This principle is the same across all fusion centers where there is a two pronged test which includes first a "right to know" and then a "need to know".

Analysts who saw their audience as a more general audience tended to see their audience in terms of the two aforementioned listservs and sought to ensure that products were tailored to the security level of the listserv to whom it was sent. In other words, the LES bulletins may have contained slightly different information based on the security level of the list, but this was the only difference. One of the respondents explained that the "customers (they) are serving are broad; that is what the basis of the fusion center is (because) it is not centered in one area... we are serving everybody from (the chief of police) who may have to make a command deployment decision based on information we are sending all the way to the public health official in (nearby county), the private sector in charge of information security or a security director at the (major league) ball park who has to brief his senior leader and security directors.” Another respondent noted they "tended to write to diverse levels of groups to get the information out to everyone." Therefore, some of the analysts try to cast a wide net because they recognize that not everyone will receive the intelligence or will even need the intelligence.

Respondents were asked to clarify who they perceived the actual audience to be when disseminating products. The research team believed this was an important difference 
because even if they intend for the products to be sent to a particular audience, the recipients may knowingly be different from the intended audience. For example, one analyst pointed out that they write and would like for the bulletins to be seen by patrol officers, especially because they are the people who would greatly utilize situational awareness and officer safety bulletins. As the respondents noted, "I make sure that the commanders have it and then it is up to the commanders to disseminate." However, "if they choose not to, then the fusion center has no input on that... Once it leaves here, there's so many different aspects of the police department, so many different units and everything that it is tough to say who the actual audience is.” Further probing questions indicated the actual audience appeared to be the same as the intended audience most of the time.

Disseminating the intelligence on the listserv was not a guarantee that it would be read by end-users. For example, while half of the analysts stated that they create products for general law enforcement, one analyst pointed out that they received feedback from officers that they "never heard about that or it never came out of the captain's office.” This may be due to an inability to formally identify the audience for all of the analysts. Analysts with more training recognized this need so that the intelligence products have more meaning or at least an increased readership: "I know that the analytic team is trying to do a better job of at least formalizing in our heads who that end-user is because it is a broad audience so some people may say 'oh well that's not for me,' but you know you do try and actually think about who the end-user is on this product.” As the respondent notes, recipients of bulletins that do not pertain to them may lose interest in all bulletins that come from the fusion center. Thus, they may divest from paying attention to products in general. 
The people that comprise the actual listserv is difficult to assess. While all of the people on the listserv have signed the necessary non-disclosure forms, many of the people on the listserv seemed to be an amalgamation of different sectors rather than a more precise assessment of all relevant stakeholders. For example, one of the supervisory analysts explained that they were not " $100 \%$ familiar with the distribution lists...I would assume that we hit all of the sectors. I know we hit private sector, I know we have law enforcement, fire is on there, and then EMS." At least one civilian analyst says that one of the "main concerns among the analysts here is that we often don't know who our end user is and what the utility it is that we're doing." However, the center continues to find holes in its listservs including schools and universities. "More and more as we get into it, there's that light that goes on that says 'we should have reached out to those people' or 'what could we have done at this level?'” There's always something new and it's a total learning process that goes on and on. It's continually being refined." This is to be expected given how much the center is trying to expand into the private sector.

\section{Feedback}

A primary reason that analysts seem to be unsure of the representation of the actual intelligence product audience is because of a lack of feedback. The feedback loop is one of the most important elements in the intelligence process because it helps analysts understand what information or intelligence is needed by the stakeholders (Carter \& Carter, 2009b; Ratcliffe, 2008). Analysts can then tailor products to maximize effectiveness for end-users. Thirty five percent of the analysts indicated they had not received feedback from any intelligence recipient; whether this was from stakeholders who received the products, other 
analysts within the fusion center, or supervisory analysts. Respondents who indicated they received no feedback were highly dissatisfied with the lack of feedback and expressed a strong desire to develop feedback channels to improve products. For instance, when asked if she received feedback, one analyst said, "That has been something that has bothered me from the beginning. One of the major steps in the intelligence cycle is feedback before you go to that next step...I have talked with leadership about this.” This was a theme among many of the civilian analysts who had transitioned from careers as analysts in other sectors or received advanced training and understood the intelligence cycle. While every analyst indicated they would like more feedback, it seemed that police analysts wanted the feedback to better understand the needs of the community; this was slightly different from the civilian analysts who wanted both feedback and information which they could then analyze for a greater variety of sources.

A large minority indicated they received feedback from various sources, but that the feedback was very minimal or not constructive. Of the feedback received, respondents indicated it was mostly general positive comments such as “Good job.” The most common type of feedback was requests for additional information. Three respondents did note that officers informed them that a product led to an arrest. When respondents were probed regarding mediums through which feedback travels, common responses were that endusers would reply to the original distribution email or a call from other fusion centers asking about a particular bulletin that had been emailed to the distribution lists. Feedback was almost never received from local law enforcement, the intended audience of the analytic products. This had the unfortunate effect of leaving at least one respondent to 
believe that "people are not engaged enough to have an opinion." This is in keeping with past literature about feedback (Lewandowski \& Carter, 2014; Ratcliffe \& Walden, 2010).

This is not because of a lack of trying on the part of the fusion center which “includes a product survey with all of our products that we send out. We're supposed to. It may go out to 1,000 people, we may get one or two back.” The analysts seemed to disagree on how many surveys were received by the center but agreed that it is still not enough to help them understand who receives the products and what more they want from the products, "We do the product surveys from time to time, we receive "good job" but for the amount of surveys going out, we receive very little back. Rarely, do we get requests that they would like to receive something in particular. I don't think we do good outreach in that way. We receive about 200 back out of 2000 surveys going out.” This idea of the importance of outreach can also be seen in another analyst's response regarding the feedback. "We're just not tied in enough with these units or have strong enough relationships with these units to really notice if it's doing anything. All we see is whether or not it was sent, and that's a success. I think that's true of a lot of intelligence agencies.” The analyst is reiterating the point that outreach helps them understand how their intelligence bulletins are being used if they cannot coerce recipients to respond to an online survey.

First, however, the end-users need to become knowledgeable about the products and many of the civilian analysts seemed to be more optimistic about the utility of their products once the potential end-users became aware of them as evidenced here: "I think people will be receptive to it; they just need a better understanding of it, and we need to make better use of the tools out there like DHS...they have got all of those different fusion 
liaisons products that we could be taking advantage of to reach people such as the firefighters, EMTs, police officers, public health officials.” As another civilian analyst pointed out, end-users cannot ask for products they do not know about: "Send me an email that says “I’d like to see a product on something...” But I don’t know if they don't engage because they don't know what they want, like we talked about before, they don't know what they want, they don't know how to reach out, or they just don't think about it. I don't know.” The analyst reiterates the frustration that all analysts either directly spoke about, or at least alluded to: the lack of feedback.

While all analysts were frustrated by the dearth of responses, police analysts tended to be a bit more pessimistic about the response to marketing efforts: One police analyst said that he goes "out to meetings, law enforcement group meetings... (and) send(s) out information over the internet, over to different groups that are out there...Generally speaking, the effort made by other people has been low.” This may point to a difference in the amount of time at the center. Many of the civilian analysts were newer, and while they were aware of many of the same problems as the police analysts, they seemed to be less jaded than the police analysts who had seen the fusion center grow from its infancy.

\section{Geographic Focus}

Related to the issue of intended audience was the geographic focus of analytic products. Approximately half of the respondents indicated the fusion center was citycentric rather than regional. As one analyst stated, "We support the region if they want us to check our database. We provide investigative support.” This is somewhat understandable given that the leadership of the fusion center and many of the analysts are employees of 
the city police force. One analyst stated that another reason for the concentration on the city was because the city "is the epi-center of this region for crime and terrorism." Large urban areas contain many of the nation's critical infrastructures which are the focus of many intelligence products.

However, respondents indicated that despite the importance of the large metropolitan area and organizational commitment to the employing agency, the fusion center should have a regional focus. As explained by one analyst, "We have a lot of critical infrastructure here that needs to be protected and that kind of thing, but again, when you are talking about trafficking, staging areas are set up in the peripheries of cities. The transportation aspect of trafficking, public airlines, trains, all of that stuff: the city is only a hub for it. Not having a visual on the data that travel generates once it leaves the city limits our ability to really provide any analysis on it.” The analyst brings up a valid point: while much of the focus of a regional fusion center is the city, analysts need to be aware that criminals travel into and out of the city to other parts of the region. The analyst went on to question whether or not a city entity should manage a regional center because it would perhaps hinder their ability to see past city borders. However, 21 percent of respondents, generally more senior-level respondents, perceived the fusion center to be trying to address this issue for the future. For example, these respondents indicated they had started to reach out to more stakeholders outside of the immediate city and even other fusion centers in the region. As pointed out by one of the supervisory analysts, though, it is also incumbent upon the region outside of the city to send resources and data to the fusion center so that analysts can use it to better assess the threats facing the whole region. 
One of the reasons that was commonly cited for the city focus was for the already mentioned operational command of the fusion center by the local police, but also the amount of resources and databases to which they have access. The analysts and employees are therefore most familiar with the city and have connections in the city. A civilian analyst who had not been at the fusion center long informed the interviewer that "there are some things we send out that have to do with (nearby states), but I feel like (the city) is the center of it...As for the people here, I would say they're definitely all city-centric. Most of the (fusion center), a lot of the personnel here, they are (city) police officers. They do have other partner agencies that are here, but again, they're based in (the city).” Another civilian analyst who was hired more recently agreed that the products and analysis had a less regional focus because of the inability of the analysts and officers to gain meaningful partnerships outside of the city. "I think once again it comes down to that it's supposed to be a regional fusion center, but it's (city) run, so there's that breaking down the barriers of going north, south, east, and west to get the other partners involved. It's supposed to be more about the partners than it is about the city.” The analyst implies that outreach to partners all over the region for purposes of receiving information is important but is more difficult without pre-existing relationships.

While all respondents, especially civilian analysts, saw outreach as critical to garnering support and receiving data and resources from outside the city, one supervisor whose affiliation was to the local police department affirmed the importance of the need for regional partners to accept the fusion center's invitation in order to truly build a regional partnership. Once again, this reaffirms the difference in views of how to create buy-in from agencies outside the city. Employees of the police department running the fusion center 
felt they had reached out to local agencies and were not receiving the feedback they had requested whereas civilian analysts, or those not employed directly by the city police department, felt that more outreach and education of the capabilities of the fusion center needed to be communicated.

\section{Discussion}

Published research using survey data has helped to identify patterns of information sharing that hold across various fusion centers and fusion center end-users. Past studies have shown us that information sharing can vary by organizational goals, perceived similarity with the agency providing the information, and simply by geographic location. This study added to the current literature by analyzing qualitative data; the study revealed that the inclusion of people into the formal system will inevitably lead to more subjectivity in the process; information sharing is hindered by the relationships that analysts maintain with other human potential sources of information. Moreover, the analysts' past experiences will influence their perceptions of the identity and needs of the audience they believe are in need of the information.

Research specifically focused on analytical personnel from information sharing organizations is limited. This gap is largely due to the difficulty associated with gaining research access to fusion centers and personnel hesitancy to share information pertaining to intelligence issues (Chermak et al., 2013). This environment of secrecy subsists despite the 78 officially recognized fusion centers and other information sharing entities such as Joint Terrorism Task Forces (JTTFs) and High Intensity Drug Trafficking Areas (HIDTAs) 
across the U.S. that are designed to collect, analyze, and disseminate information and intelligence intended to keep stakeholders aware of risks facing their jurisdictions.

The researcher undertook the study with the premise that regional fusion centers might find themselves in an advantageous position to facilitate the fusion center mission specifically and ILP more generally. The goal of this study was to analyze the perceptions of information sharing, intelligence products, and ILP practices of the employees of the analytic unit of one regional fusion center. The findings are insightful.

The study revealed very critical inferences that need to be explored in future research. To begin, the information that analysts receive should be collected through information sharing initiatives and should help to create products that are analytical in nature. This study found evidence that information sharing still poses a significant challenge due to personality clashes, a reluctance to work with others, and an over-reliance on personal relationships. This finding lends support to Carter’s (2015) assertion that interorganizational information sharing among law enforcement would benefit from improved face-to-face opportunities to develop rapport. While all of the analysts recognized the role that information sharing plays in producing better intelligence, many of the analysts felt stymied by an inability to communicate with other departments; both within and outside of the physical fusion center building. This may be due to the paramilitary chain- of-command and the practice of stove piping which may still be occurring due to fear of compromising their investigations. Respondents also surmised this attitude could be derived from hostile personalities and perhaps a desire to keep one’s case protected from outside appropriation. While this may not necessarily be the case at all fusion centers or even other police departments, this finding shows the relevance of human relationships in the information 
sharing initiative. Given the critical role of analysts, it is important to the mission of the fusion center that all who staff a fusion center support the most basic motive for a fusion center: information sharing. This finding also provides more evidence for Ratcliffe's (2008) assertion that adoption of ILP is hindered by a culture of policing that does not traditionally prioritize information sharing, and by a lack of leaders who understand the potential benefits of ILP.

Supporting the mission of a fusion center will help the analysts coordinate with other stakeholders and entities so that greater information sharing is occurring for more targeted analysis. Other information sources also need to be utilized so that bulletins are as robust as possible. The present study observed open-sources of information as a commonly utilized resource for analysts; mirroring the national sample findings of Carter and Chermak (2012). While open sources seem to be the favored source for information, at least one analyst openly stated that he believed the use of open sources was unfortunate because "once it is open source, it is pointless to put products out on things." However, the value of the fusion center is that the end-users know that the information is credible and has been vetted through participating agencies and databases so that the end-user has more confidence in the information.

One challenge fusion centers face in relying less on open source information is balancing the need to reach a large audience and the desire to disseminate intelligence that is useful. Analysts are limited by the sources they can use in putting together bulletins because of the classification level of the recipients. The only way to avoid this is to put all products on a secure portal. This is an option that some fusion centers, including more recently the fusion center under study, have considered or put into practice, but readership 
may be reduced when requiring stakeholders to sign into a secure portal instead of logging into their email.

Open sources may still be useful if the information is applied in the most beneficial manner. Analysts can use open source information to help stakeholders understand how the information applies to them. For example, if an analyst receives open source information about an attack on an embassy overseas, the analyst may analyze the information to make it more relevant to the stakeholder. Does the attack have any bearing on the local police officer in suburban America? Are there any communities in the area that might also be under attack of which the police need to be aware? These are questions that the analyst can help answer and that move the information beyond informative to useful.

Perceptions regarding the intended audience of the analytic products were intriguing. There appears to be ambiguity surrounding to whom the analysts should be tailoring the center's products. Analysts were split in their beliefs that products were intended to inform a general or law enforcement audience while other analysts wrote to more specific audiences on a case-by-case basis. However, the more precise response concerning the actual audience is most likely a hybrid of the two perceived audiences. There are three listservs to which the analysts disseminate intelligence products. Two of the lists contain law enforcement officers and have to be broken apart because there are too many people on the list. The third list is comprised of private sector stakeholders who may not have the same clearances as law enforcement, but who nonetheless need to be informed of risks facing the community. Within each list, however, there is no further break-down. Chiefs, captains, sergeants, and patrol all receive the same information even though they 
may not all need the same information. This is also the case with the private sector list which may contain stakeholders from the water, gas, or public transportation sectors. Analysts should have a particular audience in mind when creating a product rather than disseminating products for the sake of sending something out.

Moreover, as a regional fusion center, the focus of the products that are disseminated to the stakeholders within the area of responsibility (AOR) should be relevant to all people within the AOR, not just those who are in the largest urban area within this area. While the large, urban center may face more risks, this does not necessarily mean that the area surrounding the city should be neglected. Additionally, if stakeholders within the AOR who are not in the city continually receive intelligence products they feel do not relate to their needs, they may cease to read products. This could perhaps lend insight as to why the fusion center receives such little feedback. The products may simply not be viewed as important or effective by the end-users.

Finally, the study was able to help us understand how the use of police versus civilian analysts may lead to a difference in the understanding of the audience identity, the needs of the audience, as well as the ideal practices for gathering information. While police analysts understand the local landscape well and have a greater network of people to rely on for information, they may not be able to understand the needs of agencies outside their community or law enforcement. Civilian analysts, on the other hand, are formally trained in utilizing all types of open sources and understand that outreach and education is necessary for agencies outside of the fusion center to subscribe to the fusion center model.

This study is not without limitations. An ideal interview methodology would utilize a neutral location for personnel interviews to be conducted as to minimize any perceived 
employer influence. Interviews were conducted at the fusion center in an effort to minimize the burden on staff time and maximize participation in the study. Active recruitment from all areas of the fusion center could not be achieved given time and logistical constraints placed on analytic personnel in addition to the study lacking an incentive to participate beyond informing best practices and lessons learned. The present study does not capture perceptions from other personnel within the fusion center. Though the analytic personnel interviewed for this study represent 70 percent of the center's full time staff, it is plausible that other personnel within the center perceive intelligence products and intended audiences differently. Moreover, analysts may not be aware of strategic planning and initiatives ruminating from upper management and local stakeholders; an issue plaguing many aspects of police organizations (Mastrofski \& Willis, 2010). While this is a limitation of the study, it is important to understand how analysts may affect intelligence that is disseminated from the fusion center.

In addition, feedback regarding intelligence products may be channeled to other personnel within the center. As a result, a barrier to effective feedback may be within the center as opposed to a problem with end-users. A further limitation of the study is an inability to compare these findings to other research from other centers. This limitation is levied more so on the literature than the present study, but it is nonetheless impossible to provide context for how these findings relate to the perceptions of other analytic units. At best the results could be compared to studies where analysts were included in the fusion center sample (see Graphia-Joyal, 2010, Carter, 2015; Carter and Chermak, 2012; Chermak et al., 2013); however in each of these studies analysts were a minority of the sample. 
Lastly, fusion centers are highly dynamic organizations. They rely on variable funding streams (state, federal, and grant appropriations) and are responsive to environmental demands in the form of local and national threat priorities (Carter and Chermak, 2012; Carter, 2015). As a result, fusion centers may demonstrate operational improvements in the short term and thus identify remedies to the shortcomings observed in the present research. The benefit of this study having occurred during a time of organizational growth helps to illuminate the issues facing many fusion centers nationwide. The obstacles identified in the present study have been alluded to in national policy assessments of fusion centers (House of Representatives, 2013) as well as reports urging for research in this area (U.S. Senate, 2012. The present study is one of very few that have examined these organizational practices from a scholarly perspective and lends insights for future scholarship and improvements for practice.

Given these limitations, future research should explore analysts' perceptions and awareness of the strategic goals of the fusion center and how the information gathering, analysis and dissemination practices are aligned with the future of the fusion center. Additionally, the law enforcement intelligence community needs more research on how well the analysts are able to anticipate and then meet the needs of the law enforcement and private sector communities. Finally, future studies should compare the information-sharing networks of state and regional fusion centers to help understand how best to organize an information-sharing initiative. A majority of the fusion centers are organized at the state level and many sharing initiatives such as JTTFs and HIDTAs are regional; yet little is known about how this type of organizational structure affects how well information is shared. 


\section{Conclusion}

Contemporary fusion centers are designed to facilitate information sharing and intelligence analysis among disparate organizations while enhancing the analytic capability of local law enforcement to be more effectively intelligence-led. Previous research has struggled to contextualize the analytic environment of fusion centers; a capacity at the heart of the organization's mission. Findings from this research suggest that fusion center policymakers consider three action steps. First, fusion centers should seek to better understand the end-users of the analytic products they create. This pertains to both the organization types subscribed to the center to receive products, but also the geography(s) being served. It appears that intelligence products are either too general in nature or not applicable to all jurisdictions, resulting in diluted product effectiveness and less engagement with the center.

Second, the findings suggest that while some information sharing is occurring, it is best achieved through personal relationships between analysts and members of external organizations. As such, fusion centers should consider adopting (or improving) a fusion center liaison officer (FLO) program that establishes specific personnel as points of contact to develop relationships with external organizations for purposes of trustworthy and efficient information sharing (Saupp, 2010). Lastly and related to the second suggestion, fusion centers should develop feedback loops, or try to develop more effective feedback loops, to best evaluate the effectiveness of analytic products. This could potentially be achieved through a FLO program or by conducting a formal assessment on a regularly scheduled basis to ensure analytic products are continuing to meet the needs of end-users. 
This approach is consistent with the line of evidence coming from the police-researcher partnership studies that indicate the importance of personal relationships to facilitate effective partnerships for research (Rojek et al., 2015). 


\section{References}

Brod, M., Tesler, L. E., \& Christiansen, T. L. (2009). Qualitative research and content validity: Developing best practices based on science and experience. Quality of Life Research, 18(9), 1263-1278.

Burruss, G. W., Giblin, M. J., \& Schafer, J. A. (2010). Threatened globally, acting locally: Modeling law enforcement homeland security practices. Justice Quarterly, 27(1), 77-101.

Carter, D. L., \& Carter, J. G. (2009a). Intelligence-led policing: Conceptual considerations for public policy. Criminal Justice Policy Review, 20, 310-325.

Carter, D. L. \& Carter, J. G. (2009b). The intelligence fusion process for state, local and tribal law enforcement. Criminal Justice and Behavior, 36(12), 1323-1339.

Carter, J. G. (2016). Institutional pressures and isomorphism: The impact on intelligenceled policing adoption. Police Quarterly. DOI: 10.1177/1098611116639536.

Carter, J. G. (2015). Inter-organizational relationships and law enforcement information sharing post 11 September 2001. Journal of Crime and Justice, 38(4), 522-542.

Carter, J. G. \& Carter, D. L. Law enforcement intelligence: Implications for selfradicalized terrorism. Police Practice and Research, 13(2), 138-154.

Carter, J. G. \& Chermak, S. (2012). Evidence-based intelligence practices: Examining the role of fusion centers as a critical source of information. In C. Lum and L. Kennedy. (Eds). Evidence-Based Counterterrorism Policy, 65-88. New York: Springer.

Carter, J. G. \& Phillips, S. W. (2015). Intelligence-led policing and forces of organizational change in the United States. Policing \& Society, 25(4), 333-357.

Carter, J. G., Phillips, S. W. \& Gayadeen, S. M. (2014). Implementing intelligence-led policing: An application of loose-coupling theory. Journal of Criminal Justice, 42(6), 433-442.

Chermak, S., Carter, J., Carter, D., McGarrell, E. F., \& Drew, J. (2013). Law enforcement's information sharing infrastructure: A national assessment. Police Quarterly, 16(2) 211-244.

Clark, R. M. (2007). Intelligence Analysis: A Target-Centric Approach. Washington, D.C.: CQ press.

Cooney, M., Rojek, J., \& Kaminski, R. J. (2011). An assessment of the utility of a state fusion center by law enforcement executives and personnel. IALEIA Journal, 20, 1-18. 
Cope, N. (2004). Intelligence led policing or policing led intelligence? British Journal of Criminology, 44(2), 188-203.

Darroch, S., \& Mazzerolle, L. (2012). Intelligence-led policing: A comparative analysis of organizational factors influencing innovation uptake. Police Quarterly, 1-35.

Denzin, N. K. (2012). Triangulation 2.0. Journal of Mixed Methods Research, 6(2), 80-88.

Fusch, P. I. \& Ness, L. R. (2015). Are we there yet? Data saturation in qualitative research. The Qualitative Report, 20(9), 1408-1416.

Graphia-Joyal, R. (2010). Are fusion centers achieving their intended purposes? Findings from a qualitative study on the internal efficacy of state fusion centers. IALEIA Journal, 19, 54-76.

Greene, J. R. (2014). New directions in policing: Balancing prediction and meaning in police research. Justice Quarterly, 31(2), 193-228.

Guest, G., Bunce, A., \& Johnson, L. (2006). How many interviews are enough? An experiment with data saturation and variability. Field Methods, 18(1), 59-82.

Homeland Security Council. (2007) National Strategy for Homeland Security. Washington: Office of Homeland Security.

Innes, M., Fielding, N., \& Cope, N. (2005). The application of science? The theory and practice of crime intelligence analysis. British Journal of Criminology, 45(1), 3957.

King, N. (1994). The Qualitative Research Interview. In C. Cassell and G. Symon (Eds.), Qualitative Methods in Organizational Research, 14-36. Sage. London.

Lewandowski, C., \& Carter, J. G. (2014). End-user perceptions of intelligence dissemination from a state fusion center. Security Journal. Advanced online publication. DOI:10.1057/sj.2014.38.

Lewandowski, C. \& Nestel, T. (2016). : Police Communication at the Local Level: An Exploratory Study. Journal of Policing, Intelligence and Counter Terrorism.

MacDougall, C. \& Baum, F. (1997). The devil's advocate: A strategy to avoid groupthink and stimulate discussion in focus groups. Qualitative Health Research, 7(4), 532541.

Mastrofski, S., \& Willis, J. J. (2010). Police organization continuity and change: Into the twenty - first century. Crime and Justice, 39(1), 55-144. 
National Commission on Terrorist Attacks Upon the United States. (2004). The 9/11 Commission Report. Available from http://www.9-11commission.gov/

O’Reilly, M., \& Parker, N. (2013). 'Unsatisfactory Saturation': A critical exploration of the notion of saturated sample sizes in qualitative research. Qualitative Research, 13(2), 190-197.

Ratcliffe, J. H. (2002). Intelligence-led policing and the problems of turning rhetoric into practice. Policing and Society, 12(1), 53-66.

Ratcliffe, J. H. (2005). The effectiveness of police intelligence management: A New Zealand case study. Police Practice and Research, 6, 434-445.

Ratcliffe, J. H. (2008). Intelligence-Led Policing. Cullompton, UK: Willan Publishing.

Ratcliffe, J. H., \& Guidetti, R. A. (2008). State police investigative structure and the adoption of intelligence-led policing. Policing: An International Journal of Police Strategies and Management, 31, 109-128.

Ratcliffe, J. H., Strang, SJ, \& Taylor, RB. (2013). Assessing the success factors of organized crime groups: Intelligence challenges for strategic thinking. Policing: An International Journal of Police Strategies and Management, 37(1), 206-227.

Ratcliffe, J. H., \& Walden, K. (2010) State police and the intelligence center: A study of intelligence flow to and from the street, Journal of the International Association of Law Enforcement Intelligence Analysts, 19(1): 1-19.

Riley, K. J., Treverton, G. F.,Wilson, J. M., \& Davis, L. M. (2005). State and Local Intelligence in the War on Terrorism. Santa Monica, CA: Rand.

Roberts, A. \& Roberts, J. M., Jr. (2007). The structure of informal communication between police agencies. Policing 30(1): 93-107.

Rojek, J., Martin, P. \& Alpert, G. (2015). Developing and maintaining police-researcher partnerships to facilitate research use: A comparative analysis. New York: Springer.

Rosenbaum, D. P. (2002). Evaluating multi-agency anti-crime partnerships: Theory, design, and measurement issues. Crime Prevention Studies, 14, 171-225.

Saari, S. C. (2010). Fusion Centers: Securing America's Heartland from Threats. Master's thesis, Naval Postgraduate School, Monterey, CA

Sanders, C. D., Weston, C., \& Schott, N. (2015). Police innovations, 'secret squirrels' and accountability: Empirically studying intelligence-led policing in Canada. British Journal of Criminology, 55(4), 711-729. 
Saupp, K. (2010). Fusion liaison officer programs: Effective sharing of information to prevent crime and terrorism. The Police Chief, 27(2), 21-24.

Stavros, C., \& Westberg, K. (2009). Using triangulation and multiple case studies to advance relationship marketing theory. Qualitative Market Research, 12(3), 307320.

Taylor, R. W., \& Russell, A. L. (2012). The failure of police "fusion” centers and the concept of a national intelligence sharing plan. Police Practice and Research, 13, 184-200.

U.S. Department of Homeland Security. (2016). Fusion Center Locations and Contact Information. Washington, DC. Retrieved from http://www.dhs.gov/fusion-centerlocations-and-contact-information

U.S. Department of Homeland Security. (2013). 2013 Fusion Center Assessment Individual Report. Washington, DC. [Fusion center name removed for anonymity].

U.S. House of Representatives. (2013). Majority Staff Report on the National Network of Fusion Centers. Washington, DC: Committee on Homeland Security.

Weisburd, D. \& Braga, A. (2006). Police Innovation: Contrasting Perspectives. Cambridge University Press.

Weiss, A. (1998). Informal Information Sharing Among Police Agencies. National Institute of Justice. U.S. Department of Justice. Washington, DC. FS 000233.

Zegart, A. B. (2007) "CNN with Secrets:” 9/11, the CIA, and the organizational roots of failure. International Journal of Intelligence and Counter-Intelligence, 20(18), 1849. 


\section{Appendix A: 2013 Fusion Center Assessment Items Characteristics of the Fusion Center of Study}

\begin{tabular}{|c|c|}
\hline Organizational Policies and Practices & $\begin{array}{l}\text { Fusion } \\
\text { Center of } \\
\text { Study }\end{array}$ \\
\hline $\begin{array}{l}\text { Fusion center has approved plans, policies, or standard operating } \\
\text { procedures (SOP) for the receipt of federally generated threat information }\end{array}$ & Yes \\
\hline $\begin{array}{l}\text { Fusion center has a plan, policy or SOP that addresses the receipt and } \\
\text { handling of National Terrorism Advisory System (NTAS) alerts }\end{array}$ & Yes \\
\hline $\begin{array}{l}\text { Fusion center has staff with a need to access classified information are } \\
\text { cleared to at least the Secret level }\end{array}$ & Yes \\
\hline $\begin{array}{l}\text { Fusion center has access to Homeland Security Defense Network and/or } \\
\text { FBINet (i.e., within fusion center or onsite) }\end{array}$ & Yes \\
\hline Fusion center has access to sensitive but unclassified information systems & No \\
\hline $\begin{array}{l}\text { Fusion center has approved plans, policies, or SOPs for assessing the local } \\
\text { implications of time - sensitive and emerging threat information }\end{array}$ & Yes \\
\hline Fusion center has a documented analytic production plan & Yes \\
\hline $\begin{array}{l}\text { Fusion center has access to multidisciplinary subject matter experts (SME) } \\
\text { within its area of responsibility (AOR) to inform analytic production }\end{array}$ & No \\
\hline $\begin{array}{l}\text { Fusion center has access to other fusion centers' multidisciplinary SMEs } \\
\text { outside of its state to inform analytic production, as required }\end{array}$ & Yes \\
\hline $\begin{array}{l}\text { Fusion center has a process to provide DHS with information and/or } \\
\text { intelligence that offers a local context to threat information in the event of } \\
\text { an NTAS - related alerts }\end{array}$ & Yes \\
\hline Fusion center conducts threat assessments within its AOR & No \\
\hline $\begin{array}{l}\text { Fusion center contributes to or conducts a statewide risk assessment (threat, } \\
\text { vulnerability, and consequence analysis) }\end{array}$ & No \\
\hline Fusion center contributes to national - level risk assessments & No \\
\hline $\begin{array}{l}\text { Fusion center has a customer satisfaction mechanism for its analytic } \\
\text { products }\end{array}$ & Yes \\
\hline $\begin{array}{l}\text { Fusion center evaluates the effectiveness of the customer feedback } \\
\text { mechanism on an annual basis }\end{array}$ & Yes \\
\hline $\begin{array}{l}\text { All fusion center analysts have received at least } 20 \text { hours of issue - specific } \\
\text { training in the past } 12 \text { months }\end{array}$ & No \\
\hline $\begin{array}{l}\text { Fusion center has approved plans, policies or SOPs governing the } \\
\text { procedures for the timely dissemination of products to customers within its } \\
\text { AOR }\end{array}$ & Yes \\
\hline Fusion center has a dissemination matrix & Yes \\
\hline $\begin{array}{l}\text { Fusion center has a primary sensitive but unclassified mechanism to } \\
\text { disseminate time sensitive information and products }\end{array}$ & Yes \\
\hline $\begin{array}{l}\text { Fusion center has a plan, policy or SOP that addresses dissemination of } \\
\text { NTAS alerts to stakeholders within its AOR }\end{array}$ & Yes \\
\hline Fusion center has a mechanism to disseminate NTAS alerts & Ye \\
\hline
\end{tabular}




\begin{tabular}{|c|c|}
\hline $\begin{array}{l}\text { Fusion center has a process for verifying the delivery of products to } \\
\text { intended customers }\end{array}$ & No \\
\hline $\begin{array}{l}\text { Fusion center has an approved NSI Site plan or an approved plans, policies } \\
\text { or SOPs governing the gathering of locally generated information }\end{array}$ & Yes \\
\hline Fusion center has a tips and leads process & Yes \\
\hline Fusion center has a process for identifying and managing information needs & Yes \\
\hline $\begin{array}{l}\text { Fusion center has a process for managing the gathering of locally - } \\
\text { generated information to satisfy the fusion center's information needs }\end{array}$ & Yes \\
\hline Fusion center has approved Standing Information Needs (SINs) & Yes \\
\hline Fusion center has an annual process to review and refresh SINs & Yes \\
\hline $\begin{array}{l}\text { Fusion center has a process to inform DHS of protective measures } \\
\text { implemented within its AOR in response to an NTAS alert }\end{array}$ & Yes \\
\hline Fusion center has a request for information management process & Yes \\
\hline $\begin{array}{l}\text { Fusion center has a privacy policy determined by DHS to be at least as } \\
\text { comprehensive as the Information Sharing Environment Privacy Guidelines }\end{array}$ & Yes \\
\hline $\begin{array}{l}\text { Fusion center provides formal and standardized training to all personnel on } \\
\text { the fusion center's privacy policy annually }\end{array}$ & Yes \\
\hline $\begin{array}{l}\text { Fusion center's policies, processes, and mechanisms for receiving, } \\
\text { cataloging, and retaining information (provided to the center) comply with } \\
28 \text { C.F.R. Part } 23\end{array}$ & Yes \\
\hline $\begin{array}{l}\text { Fusion center trains all personnel who access criminal intelligence systems } \\
\text { in } 28 \text { C.F.R. Part } 23\end{array}$ & Yes \\
\hline Fusion center has identified a Privacy/CRCL Officer for the center & No \\
\hline Fusion center has a privacy policy outreach plan & No \\
\hline Fusion center has an approved strategic plan & No \\
\hline Fusion center conducts an annual financial audit & Yes \\
\hline Fusion center completes annual operational cost assessment & Yes \\
\hline Fusion center conducts an exercise at least once a year & No \\
\hline $\begin{array}{l}\text { Fusion center measures its performance and determines the effectiveness of } \\
\text { its operations relative to expectations it or its governing entity have defined }\end{array}$ & No \\
\hline $\begin{array}{l}\text { Fusion center has a designated Public Information Officer or Public Affairs } \\
\text { Officer }\end{array}$ & Yes \\
\hline Fusion center has an approved communication plan & No \\
\hline Fusion center has a process for capturing success stories & Yes \\
\hline $\begin{array}{l}\text { Fusion center has an approved security plan that addresses personnel, } \\
\text { physical and information security }\end{array}$ & No \\
\hline Fusion center trains all personnel on the fusion center's security plan & No \\
\hline Fusion center has a designated Security Liaison & Yes \\
\hline $\begin{array}{l}\text { Fusion center's Security Liaison (or other organization's Security Liaison) } \\
\text { completes annual training }\end{array}$ & No \\
\hline Fusion center has access to the Central Verification System (CVS) & No \\
\hline $\begin{array}{l}\text { Fusion center's Security Liaison (or other organization’s Security Liaison) } \\
\text { is trained on how to use CVS }\end{array}$ & No \\
\hline
\end{tabular}




\section{Appendix B: Interview Protocol Regional Fusion Center of Study}

Interview Number:

Date:

* Interviews were preceded with an explanation of project participation and consent as well as a project introduction and overview from research team members.*

**Some interview questions have been modified to protect the anonymity of the center of study.**

\section{Respondent Information}

Please describe your position within the fusion center.

Please describe your professional background.

\section{Development of Intelligence Products}

Can you please describe the types of intelligence products you create?

Probe: Which types of products do you create most often? Why?

Probe: Which products do you believe are most useful by the recipients?

Probe: Are there products you believe recipients want, or could use, that are not being created by the fusion center? If so, please explain.

Can you please describe the sources of information and data that you use when creating intelligence products?

Probe: Which sources of information are most useful and do you most frequently utilize?

Can you please explain how intelligence products are formatted and organized?

Probe: Does the format and organization of intelligence products vary, or depend on, certain factors? More specifically, does the format of intelligence products vary depending on the security level, intended audience, product type, or dissemination method?

Has your fusion center identified information requirements? More specifically, has your center identified the types of intelligence products most desired by recipients?

Probe: If yes or no, please describe how, why, or why not. 
Has the fusion center received any feedback from participating and/or peer organizations regarding the types of products they wish to receive from the DVIC?

If yes, please describe.

If no, why do you think this is? Do you believe is feedback needed?

\section{Dissemination of Intelligence Products}

Can you please describe the method(s) for disseminating intelligence products?

Probe: Which method(s) are most commonly used? Why?

Can you please describe the security and clearance level of the intelligence products disseminated by the fusion center (such as FOU, Unclassified, LES, etc.)?

Probe: Which security or clearance level is most common? Why?

Can you describe the recipients of the fusion centers products? More specifically, who is the intended audience, or audiences, that receive the intelligence products?

Probe: Are different products created for different recipients?

Probe: Are you aware of the types of recipients to which you disseminate intelligence products?

If yes, please describe.

If no, please explain why not? Or do you believe you need to know?

Can you please describe the frequency of the intelligence product dissemination?

Probe: Does the frequency vary by type of product. If so, in what ways?

Who is responsible for disseminating intelligence products from the fusion center? More specifically, do analysts disseminate products once they are completed? Or does a supervisor review and then distribute? Please explain.

Can you please describe the process through which dissemination listservs are created? Probe: How does an organization go about being included on the dissemination list to receive products?

Probe: Do organizations ever request to unsubscribe to the listserv? If so, why?

\section{Awareness of the Fusion Center}

Has your fusion center communicated to other law enforcement the resources, or services, the center can provide?

If so, please explain how.

If not, why not? 
Has your fusion center attempted to market the fusion center to external organizations that are both law enforcement and non-law enforcement (such as private sector or public health)?

If yes, how so and to whom?

If not, why not and do you believe it is necessary?

Do you believe intelligence products and dissemination methods from your fusion center will change in the future? Please explain.

Given there are other fusion centers located within the similar geographic proximity of your center, does your center attempt to provide unique intelligence products that are more relevant to local criminal/threat issues? Please explain.

How do you envision the role of your fusion centers as compared/contrasted to the other fusion centers in your region?

***Each interview concluded by thanking respondents for their time and providing each respondent with research team contact information (that was also available in the consent document). 